
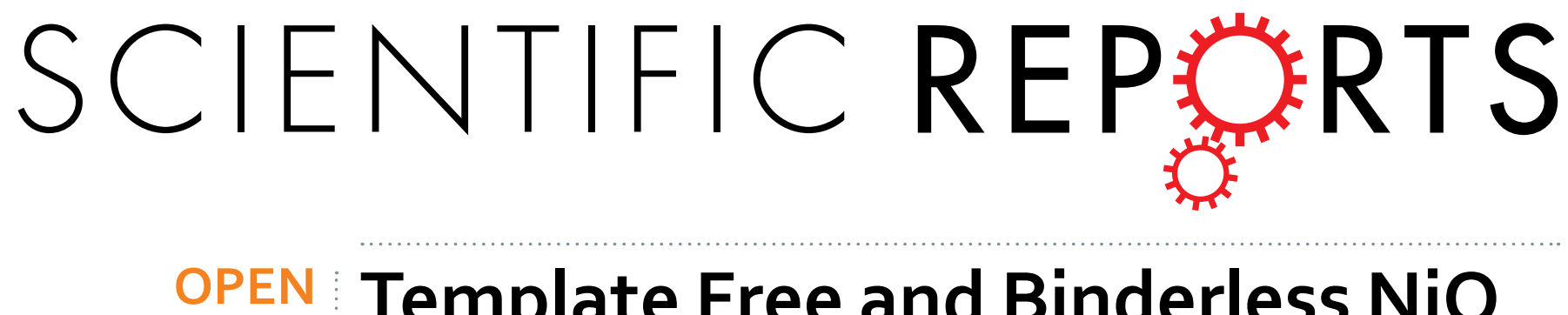

\title{
Template Free and Binderless NiO Nanowire Foam for Li-ion Battery Anodes with Long Cycle Life and \\ Ultrahigh Rate Capability
}

Received: 18 March 2016

Accepted: 02 June 2016

Published: 18 July 2016

\author{
Chueh Liu ${ }^{1}$, Changling Li ${ }^{1}$, Kazi Ahmed ${ }^{2}$, Zafer Mutlu ${ }^{1}$, Cengiz S. Ozkan ${ }^{1,3}$ \& Mihrimah Ozkan ${ }^{1,2}$
}

Herein, NiO-decorated Ni nanowires with diameters ca. 30-150 nm derived from Ni wire backbone (ca. $2 \mu \mathrm{m}$ in diameter) is directly synthesized on commercially available Ni foam as a renovated anode for $\mathrm{Li}$-ion batteries. Excellent stability with capacity $680 \mathrm{mAh} \mathrm{g}^{-1}$ at $0.5 \mathrm{C}\left(1 \mathrm{C}=718 \mathrm{~mA} \mathrm{~g}^{-1}\right)$ is achieved after 1000 cycles. Superior rate capability is exhibited by cycling at extremely high current rates, such as $20 \mathrm{C}$ and $50 \mathrm{C}$ with capacities ca. 164 and $75 \mathrm{mAh} \mathrm{g}^{-1}$, respectively. The capacity can be recovered back to ca. $430 \mathrm{mAhg}^{-1}$ in 2 cycles when lowered to $0.2 \mathrm{C}$ and stably cycled for 430 times with capacity $460 \mathrm{mAh} \mathrm{g}^{-1}$. The NiO nanowire foam anode possesses low equivalent series resistance ca. $3.5 \Omega$, resulting in superior power performance and low resistive losses. The NiO nanowire foam can be manufactured with bio-friendly chemicals and low temperature processes without any templates, binders and conductive additives, which possesses the potential transferring from lab scale to industrial production.

In recent times, electric vehicles $(\mathrm{EVs})^{1}$ are vigorously investigated and developed to diminish the dependence on fossil fuels and alleviate the deterioration of natural environment. Hybrid (HEV) and plug-in (PEV) hybrid EVs ${ }^{2}$ utilizing both batteries and internal combustion engines (ICEs) can partially resolve these issues, but the consumption of gasoline and emission of greenhouse gases from ICEs still remain problematic. Pure EVs powered by purely lithium ion batteries (LIBs) can totally eliminate these difficulties. However, the cruise range of pure EVs is still limited, such as ca. 300 miles per charge of Tesla Model S ${ }^{3}$. Accordingly, it is crucial to improve the capacity and energy density of LIBs while maintaining the power density simultaneously. Capacity of traditional graphite anode with potential ca. $0.2 \mathrm{~V}$ vs. $\mathrm{Li}$ is limited to theoretically $372 \mathrm{mAh} \mathrm{g}^{-1}$ and practically ca. $310 \mathrm{mAh} \mathrm{g}^{-1}$ for $\mathrm{LiC}_{6}$ as a result of intercalation reactions ${ }^{2}$. Higher energy density and capacity can be reached by utilizing conversion reactions of metal oxides, such as $\mathrm{FeO}, \mathrm{CoO}, \mathrm{NiO}$ and $\mathrm{CuO}^{4,5}$, in potential range $0.01-3 \mathrm{~V}$ vs. $\mathrm{Li}$ with ca. $700 \mathrm{mAh} \mathrm{g}^{-1}$ by the equation $\mathrm{MO}+2 \mathrm{Li}^{+}+2 \mathrm{e}^{-}=\mathrm{M}+\mathrm{Li}_{2} \mathrm{O}^{2,6}$. Among these, $\mathrm{NiO}$ is appealing owing to its high theoretical capacity $\left(718 \mathrm{mAh} \mathrm{g}^{-1}\right)$, environmental benignity and low cost ${ }^{6}$. Nonetheless, it still suffers from low cycling stability and low rate capability resulting from large volume expansion and poor electrical conductivity, respectively ${ }^{7}$.

To overcome these barriers, various $\mathrm{NiO}$ nanostructures have been developed to accommodate mechanical strain during cycling, to improve electrical contact and shorten ion diffusion length to reduce resistivity ${ }^{6-9}$. Three-dimensional curved $\mathrm{NiO}$ nanomembranes synthesized by electron beam evaporation demonstrate high capacity $\left(721 \mathrm{mAh} \mathrm{g}^{-1}\right)$ at $1.5 \mathrm{C}$ over 1400 cycles and high rate capability at 50C with ca. $60 \mathrm{mAh}$ per gram ${ }^{8}$. However, costly processes relying on high vacuum system prevent it from large scale production. NiO nanorods anchored on $\mathrm{Ni}$ foam by anodization in oxalic acid at $50 \mathrm{~V}$ followed by annealing in air at $400^{\circ} \mathrm{C}$ exhibit $706 \mathrm{mAh} \mathrm{g}^{-1}$ at $1 \mathrm{~A}$ per gram $^{7}$. Nevertheless, high voltage anodization utilizing electricity renders the process expensive. Relatively thick wall of the nanorods $(200-500 \mathrm{~nm}$ ) result in rapid Coulombic efficiency drop to ca. $98 \%$ after only 70 cycles $^{7}$. NiO nanofibers with diameters ca. $100 \mathrm{~nm}$ prepared by electrospinning and air annealing at $800{ }^{\circ} \mathrm{C}$ show maximum capacity $784 \mathrm{mAh} \mathrm{g}^{-1}$ at $80 \mathrm{~mA} \mathrm{~g}^{-1}$ with low capacity retention (ca. $75 \%$ ) after $100 \mathrm{cycles}^{6}$. The addition of carbon additive and binder further decrease the specific capacity of the electrode. $\mathrm{Ni} / \mathrm{NiO}$ nanofoam

${ }^{1}$ Materials Science and Engineering Program, University of California, Riverside, CA, USA. ${ }^{2}$ Department of Electrical Engineering, University of California, Riverside, CA, USA. ${ }^{3}$ Department of Mechanical Engineering, University of California, Riverside, CA, USA. Correspondence and requests for materials should be addressed to C.S.O. (email: cozkan@engr.ucr.edu) or M.O. (email: mihri@ece.ucr.edu) 
with skeleton diameter 200-300 $\mathrm{nm}$ formed by burning nickel nitrate with 2-methoxyethanol followed by oxidation at $350^{\circ} \mathrm{C}$ leads to $835 \mathrm{mAh} \mathrm{g}^{-1}$ at $0.5 \mathrm{C}$ after $200 \mathrm{cycles}^{9}$. However, long cycle stability is still questionable since capacity retention is only $85 \%$ after 200 cycles. Accordingly, $\mathrm{NiO}$ nanostructures with high capacity, energy density, rate capability and cycling stability are still highly desired.

Since $\mathrm{NiO}$ can be derived from $\mathrm{Ni}$ metal simply by annealing in air, $\mathrm{NiO}$ nanostructures can be obtained if $\mathrm{Ni}$ can be fabricated into nano-sized framework ${ }^{9,10}$. Commercial nano-Ni foam composed of Ni nanowires deposited with $\mathrm{SnO}_{2}$ by atomic layer deposition is shown to produce good stability, high capacity and rate performance in Li-ion anode ${ }^{11}$. Nanofoams composed of Ni nanowires $(100-1000 \mathrm{~nm}$ dia.) can be created by refluxing glycerol and nickel acetate $\left(\mathrm{Ni}(\mathrm{Ac})_{2}\right)$ at ca. $300-400^{\circ} \mathrm{C}$ and atmospheric pressure ${ }^{10,12}$. Surface area of Ni metal can be further enlarged to Ni oxalate nanowires or nanosheets by oxalic acid etching ${ }^{13}$, while Ni metal phase can be resumed by annealing Ni oxalate under reducing or inert atmospheres ${ }^{14-16}$. In this work, NiO-decorated Ni nanowires (dia. ca. $30-150 \mathrm{~nm}$ ) derived from micro-sized $\mathrm{Ni}$ wire backbone (ca. $2 \mu \mathrm{m}$ in dia.) is directly grown on $\mathrm{Ni}$ foam as an innovated anode for Li-ion batteries. Micro-sized Ni wires are synthesized on $\mathrm{Ni}$ foam by heating with $\mathrm{Ni}(\mathrm{Ac})_{2} /$ glycerol solution at $400^{\circ} \mathrm{C}$. Ni oxalate nanoneedles (dia. ca. $30-70 \mathrm{~nm}$ ) are derived from Ni wires by oxalic acid treatment at $80^{\circ} \mathrm{C}$ to further increase the surface area of the electrode. Ni nanowires can be obtained by reducing $\mathrm{Ni}$ oxalate nanoneedles with hydrogen at $350^{\circ} \mathrm{C}$. NiO is formed on $\mathrm{Ni}$ nanowires by calcination in air from 350 to $450^{\circ} \mathrm{C}$. This $\mathrm{NiO}$ anode demonstrates high stability with capacity $680 \mathrm{mAh} \mathrm{g}^{-1}$ after $1000^{\text {th }} \mathrm{cycle}$ at $0.5 \mathrm{C}$, where $1 \mathrm{C}=718 \mathrm{~mA} \mathrm{~g}^{-1}$. Even though the anode is cycled at extremely high current rate, such as $20 \mathrm{C}$ and $50 \mathrm{C}$, the capacities can still be ca. 164 and $75 \mathrm{mAh} \mathrm{g}^{-1}$, respectively, which exhibit the good rate capability of this nanostructured $\mathrm{NiO}$ anode. This carbon-less and binder-less $\mathrm{NiO}$ nanowire foam (NWF) anode possesses low equivalent series resistance (ESR) ca. $3.5 \Omega$, resulting in superior power performance and low resistive losses. The NiO NWF can be manufactured with eco-friendly chemicals, low temperature processes without any templates, binders and conductive additives, which might be easily transferred from lab scale to massive production.

\section{Methods}

Materials synthesis. Ni foam (MTI Corp., EQ-bcnf- $16 \mathrm{~m}$ ) with $15 \mathrm{~mm}$ diameter was first flattened to thickness ca. $120 \mu \mathrm{m}$. Flat $\mathrm{Ni}$ foam was immersed in a $10 \mathrm{ml}$ beaker filled with a solution of $2.5 \mathrm{ml} 0.08 \mathrm{M}$ nickel acetate tetrahydrate $\left(\mathrm{Ni}(\mathrm{Ac})_{2} \bullet 4 \mathrm{H}_{2} \mathrm{O}\right.$, Sigma-Aldrich, 98\%) in glycerol (Acros, $99+\%$ ) heated at $400^{\circ} \mathrm{C}$ on a hotplate for 40 min without stirring with $\mathrm{Al}$ foil cover to prevent excess solvent evaporation ${ }^{10}$. After growth, Ni wires attached on $\mathrm{Ni}$ foam were washed with deionized water 15 times to remove extra glycerol and $\mathrm{Ni}$ ions, and dried on a hotplate at $120^{\circ} \mathrm{C}$ for $5 \mathrm{~min}$. Magnetic stir rotor inside the hotplate provided the magnetic field for the alignment of Ni wire growth. Total Ni wire weight attached on $\mathrm{Ni}$ foam was ca. 7.5 to $8 \mathrm{mg}$. Freshly prepared $2 \mathrm{ml}$ solution of $0.3 \mathrm{M}$ oxalic acid dihydrate (ICN Biomedicals Inc., reagent grade) in ethanol (Decon Lab. Inc., 200 proof) with 10 wt $\%$ deionized water was used to etch the Ni wires at $80^{\circ} \mathrm{C}$ for $1.5 \mathrm{~h}$ on hotplate into Ni oxalate needle-like nanostructures ${ }^{13}$, which were further reduced back to Ni nanowires in a tube furnace with $\mathrm{H}_{2}(50 \mathrm{sccm}), \mathrm{Ar}(100 \mathrm{sccm})$

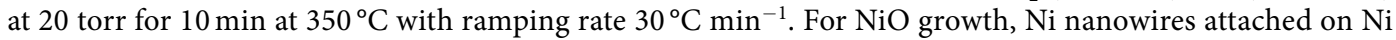
foam were heated in a tube furnace flowed with air from room temperature to $450^{\circ} \mathrm{C}$ with ramping rate $2^{\circ} \mathrm{C}$ $\mathrm{min}^{-1}$, and the $\mathrm{NiO}$-decorated Ni NWF electrode was taken out of the furnace immediately without holding at elevated temperature to control the oxide loading. $\mathrm{NiO}$ loading was equal to $\Delta \mathrm{m}^{*}$ [M.W. of $\left.\mathrm{NiO}\right] /[\mathrm{M} . \mathrm{W}$. of O] $=$ $\Delta \mathrm{m} * 74.69 / 16$, where $\Delta \mathrm{m}$ is the weight difference of the electrode before and after oxidation according to the reaction $2 \mathrm{Ni}+\mathrm{O}_{2}=2 \mathrm{NiO}^{9}$. $\mathrm{NiO}$ loading was ca. $0.5 \mathrm{mg} \mathrm{cm}^{-2}$ per electrode.

Materials characterization. Surface morphology and elemental analysis were performed by scanning electron microscopy (SEM, FEI NovaNanoSEM 450) with energy dispersive X-ray spectroscopic (EDX) detector. Crystal structures were examined by X-ray diffraction (XRD, PANalytical Empyrean) with $\mathrm{Cu}-\mathrm{K} \alpha$ radiation. Raman spectroscopy (Renishaw DXR) utilizing $532 \mathrm{~nm}$ laser with $8 \mathrm{~mW}$ excitation power and 100x objective lens was used to characterize $\mathrm{NiO}$ NWF electrode. Chemical states of $\mathrm{NiO}$ were examined by X-ray photoelectron spectroscopy (XPS, Kratos AXIS ULTRA DLD XPS system) with Al K $\alpha$ monochromated X-ray source and 165-mm mean radius electron energy hemispherical analyzer. Thermogravimetric analysis (TGA, TA instruments, SDT Q600) was performed on the electrode with air from room temperature to $700{ }^{\circ} \mathrm{C}$ with $2{ }^{\circ} \mathrm{C} \mathrm{min}{ }^{-1}$ to determine the weight change and oxidation temperature of the NiO NWF electrode. $\mathrm{N}_{2}$ adsorption/desorption for Brunauer-Emmett-Teller (BET) surface were measured on NiO NWF electrodes at $77 \mathrm{~K}$ on a Micromeritics ASAP 2020 analyzer.

Electrochemical Impedance Spectroscopy. Electrochemical performance of the NiO NWF anode was evaluated in two-electrode half-cell configuration with Li foil (MTI Corp.) counter electrode in CR2032 coin cell (MTI Corp.) using electrolyte comprising $1 \mathrm{M} \mathrm{LiPF}_{6}$ (Sigma-Aldrich, battery grade) in fluoroethylene carbonate (FEC, Sigma-Aldrich, 99\%) and dimethyl carbonate (DMC, Sigma-Aldrich, anhydrous) in FEC:DMC 1:1 (v/v) ratio. Cells were assembled in an Ar filled glovebox (VAC Omni-lab) with moisture and oxygen concentration below $1 \mathrm{ppm}$. Porous membrane (Celgard 3501) was used as the separator. Cyclic voltammetry (CV) was scanned at $0.1 \mathrm{mV} \mathrm{s}^{-1}$ in the range 3.0 to $0.02 \mathrm{~V}$ (vs. $\mathrm{Li}_{/} / \mathrm{Li}^{+}$) with Biologic VMP3. Galvanostatic charge-discharge and cycling measurements were investigated in 3.0 to $0.02 \mathrm{~V}$ (vs. $\mathrm{Li} / \mathrm{Li}^{+}$) with various current rates by Arbin BT2000. Electrochemical impedance spectroscopy (EIS) at $\mathrm{E}_{\mathrm{we}}=3.0 \mathrm{~V}$ (vs. $\mathrm{Li} / \mathrm{Li}^{+}$) between $10 \mathrm{mHz}$ to $1 \mathrm{MHz}$ with amplitude $10 \mathrm{mV}$ were performed with Biologic VMP3.

\section{Results and Discussion}

Porous $\mathrm{NiO} \mathrm{NWF}$ anode with large surface area can accommodate volume expansion during lithiation/delithiation, allow fast lithium ion transportation and provide intimate contact between the active materials and the current collector. Synthetic procedures and the scanning electron microscopic (SEM) images of the NiO NWF are 

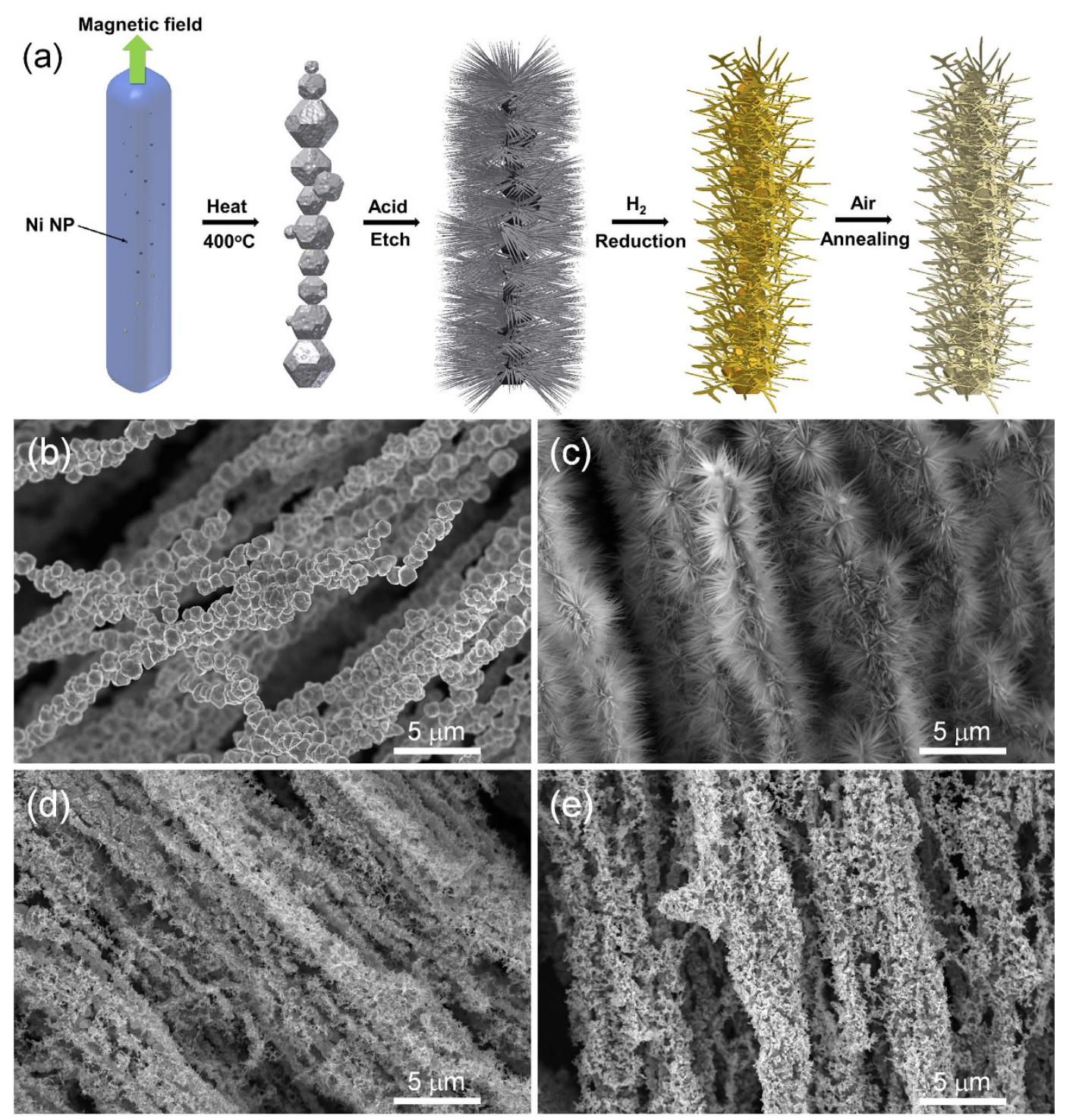

Figure 1. (a) Schematic of synthesis of NiO nanowire foam (NWF). SEM images of (b) Ni wires, (c) Ni oxalate nanoneedles, (d) Ni nanowires and (e) NiO NWF.

shown in Fig. 1. Ni foam is directly immersed in a solution of $0.08 \mathrm{M} \mathrm{Ni}(\mathrm{Ac})_{2} /$ glycerol at $400^{\circ} \mathrm{C}$ and atmospheric pressure. $\mathrm{Ni}^{2+}$ ions reduced by glycerol nucleate into $\mathrm{Ni}$ polyhedral nanoparticles which are further grown into micro-sized Ni wires under the magnetic field of the magnetic stir rotor inside the hotplate (Fig. 1a,b). The practicability of template-less and self-assembled synthesis of ferromagnetic materials into nanowires has been shown by metallic $\mathrm{Ni}$ nanowire nonwoven clothes as potential $\mathrm{NiO}$ anode for $\mathrm{Li}$-ion batteries ${ }^{17}$. The as-synthesized $\mathrm{Ni}$ wires demonstrate X-ray diffraction (XRD) peaks at $45.1^{\circ}, 52.5^{\circ}$ and $76.9^{\circ}$, revealing the characteristic of $\mathrm{Ni}$ metal phase (ref. code: 01-070-0989, Fig. 2a). The surface area of the Ni wires can be increased by etching in $0.3 \mathrm{M}$ oxalic acid/ethanol solution with $10 \mathrm{wt} \%$ water at $80^{\circ} \mathrm{C}$ (Fig. 1c) by the formation of Ni oxalate nanowires, the existence of which is indicated by XRD peaks at $18.9^{\circ}, 23.0^{\circ}, 30.4^{\circ}, 35.8^{\circ}$, and $41.2^{\circ}$ (Fig. $2 \mathrm{a}, \mathrm{NiC}_{2} \mathrm{O}_{4} \bullet 2 \mathrm{H}_{2} \mathrm{O}$, ref. code 00-014-0742). By hydrogen reduction at $350^{\circ} \mathrm{C}$, Ni oxalate can transform completely into Ni nanowire (Fig. 1d, Supplementary Fig. S1a,c) with the XRD patterns showing only Ni metallic phase without the presence of Ni oxalate (Fig. 2a). By annealing in air to $450^{\circ} \mathrm{C}$, the Ni NWF can be covered with NiO layer (Fig. 1e, Supplementary Fig. S1b,d), XRD patterns of which show peaks at $37.2^{\circ}, 43.4^{\circ}$ and $63.0^{\circ}$ (Fig. 2a, ref. code $01-071-$ $6719)$ along with the metallic Ni patterns from the underlying Ni nanowires and Ni foam. Nitrogen adsorptiondesorption isotherms and pore size distribution of NiO NWF (Supplementary Fig. S1e,f) exhibit mesoporous nature of the active materials. BET surface area of the NiO NWF is $143.43 \mathrm{~m}^{2} \mathrm{~g}^{-1}$, demonstrating the high specific surface area of the electrode. Uniform distribution of $\mathrm{NiO}$ on the Ni NWF is displayed by energy dispersive X-ray spectroscopic (EDX) analysis and elemental mapping (Supplementary Fig. S2). The existence of NiO is further demonstrated by Raman spectrum (Fig. 2b) showing four broad peaks corresponding to one-phonon longitudinal optical mode $\left(\mathrm{LO} \text { at } 531 \mathrm{~cm}^{-1}\right)^{8}$, two-phonon transverse optical mode $\left(2 \mathrm{TO} \text { at } 722 \mathrm{~cm}^{-1}\right)^{18}$, TO $+\mathrm{LO}$ (at 

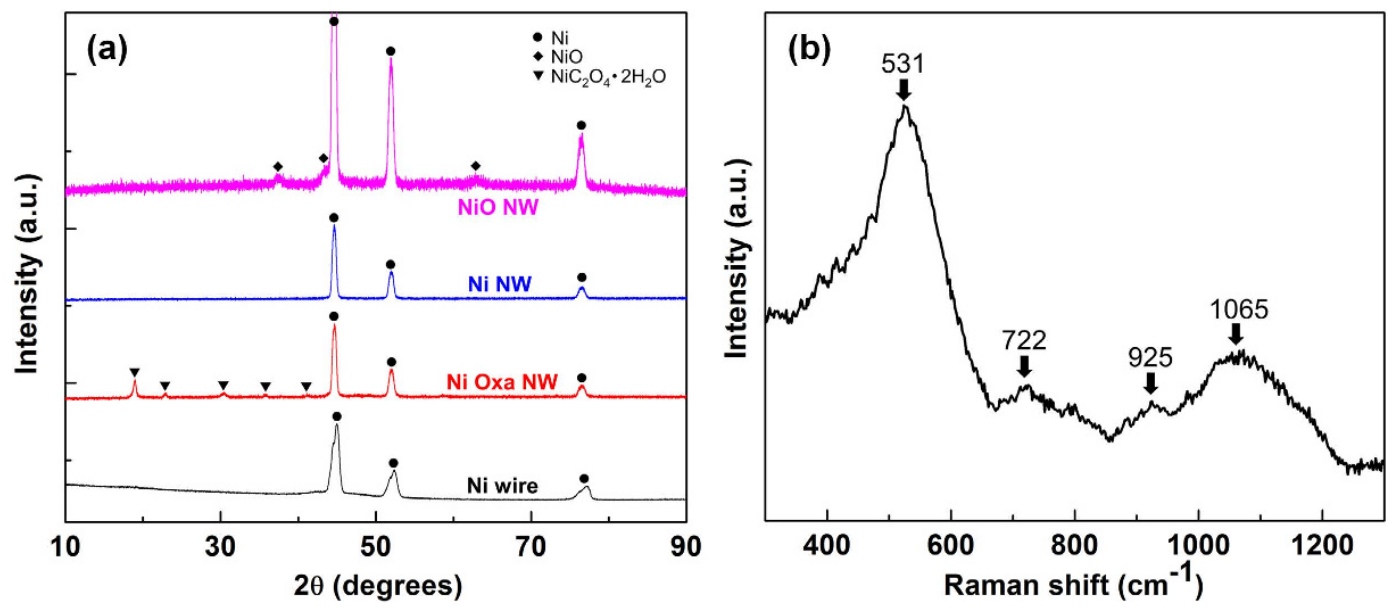

Figure 2. (a) XRD patterns of Ni wire, Ni oxalate nanowire (Ni Oxa NW), Ni nanowire (Ni NW) foam, and $\mathrm{NiO}$ NW foam. (b) Raman spectrum of the NiO NWF.
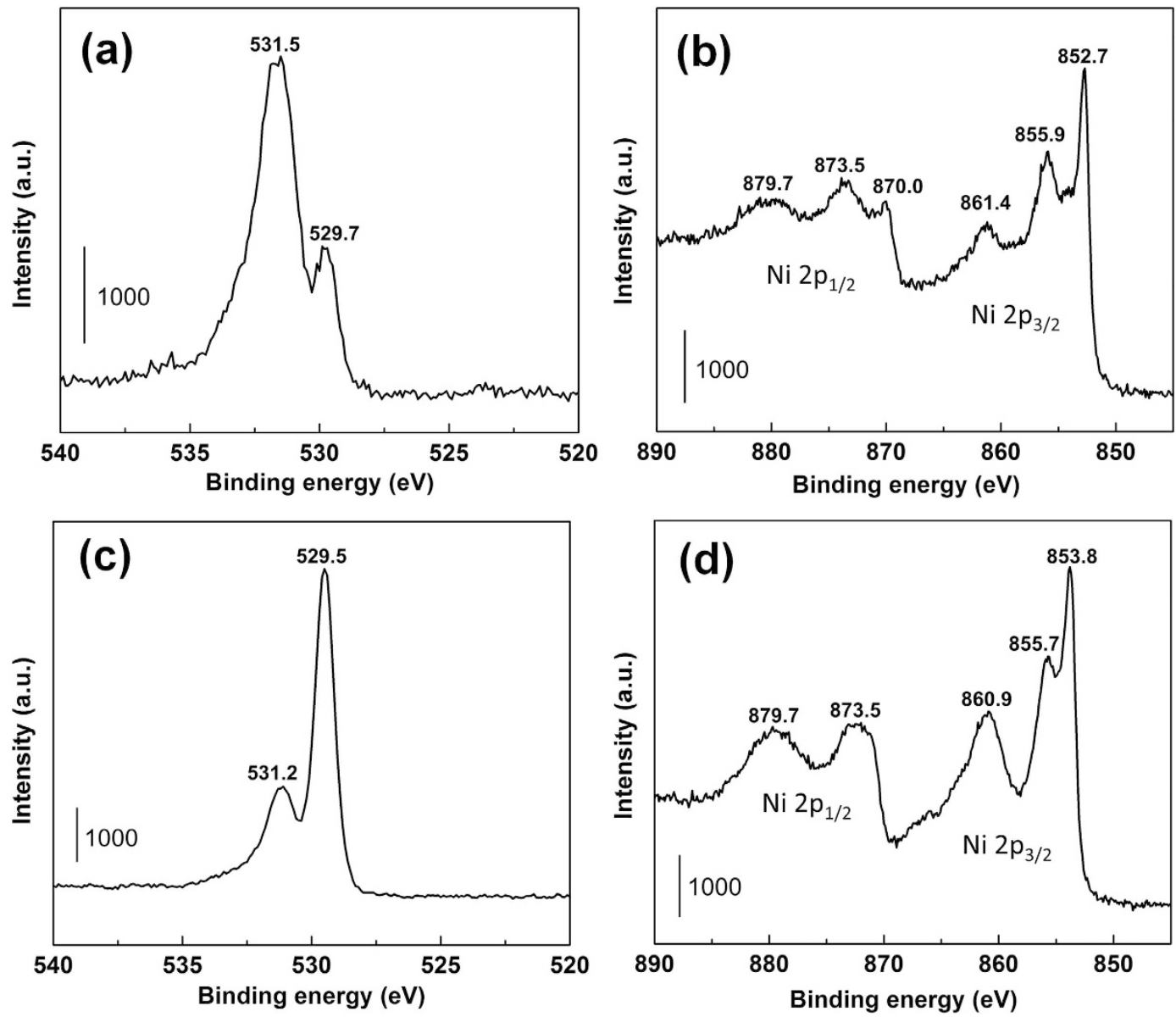

Figure 3. XPS spectrum of Ni NWF for (a) O 1s and (b) Ni 2p levels, and of NiO NWF for (c) O 1s and (d) Ni $2 \mathrm{p}$ levels.

$\left.925 \mathrm{~cm}^{-1}\right)^{18}$ and 2LO (at $\left.1065 \mathrm{~cm}^{-1}\right)^{8}$ modes. Thermogravimetric analysis (TGA, Supplementary Fig. S3) indicates $\mathrm{NiO}$ formation starts from $\mathrm{ca} .350^{\circ} \mathrm{C}$ and the Ni NWF is continuously oxidized with elevated temperature.

$\mathrm{Ni}$ and NiO NWF are investigated by X-ray photoelectron spectroscopy (XPS) to determine the valence states and composition with $\mathrm{O} 1 \mathrm{~s}$ and $\mathrm{Ni} 2 \mathrm{p}$ core levels (Fig. 3). For Ni NWF, O 1s peaks (Fig. 3a) at ca. $531.5 \mathrm{eV}$ and $529.7 \mathrm{eV}$ are attributed to $\mathrm{Ni}^{3+}$ from $\mathrm{Ni}_{2} \mathrm{O}_{3}$ and $\mathrm{Ni}^{2+}$ from $\mathrm{NiO}$, respectively, with stronger intensity from $\mathrm{Ni}^{3+}$ since a $\mathrm{Ni}_{2} \mathrm{O}_{3}$ layer tends formed on metallic nickel in air ${ }^{19}$. For $\mathrm{NiO} \mathrm{NWF}$, the $\mathrm{O} 1 \mathrm{~s}$ peak of $\mathrm{Ni}^{2+}$ at ca. $529.5 \mathrm{eV}$ 

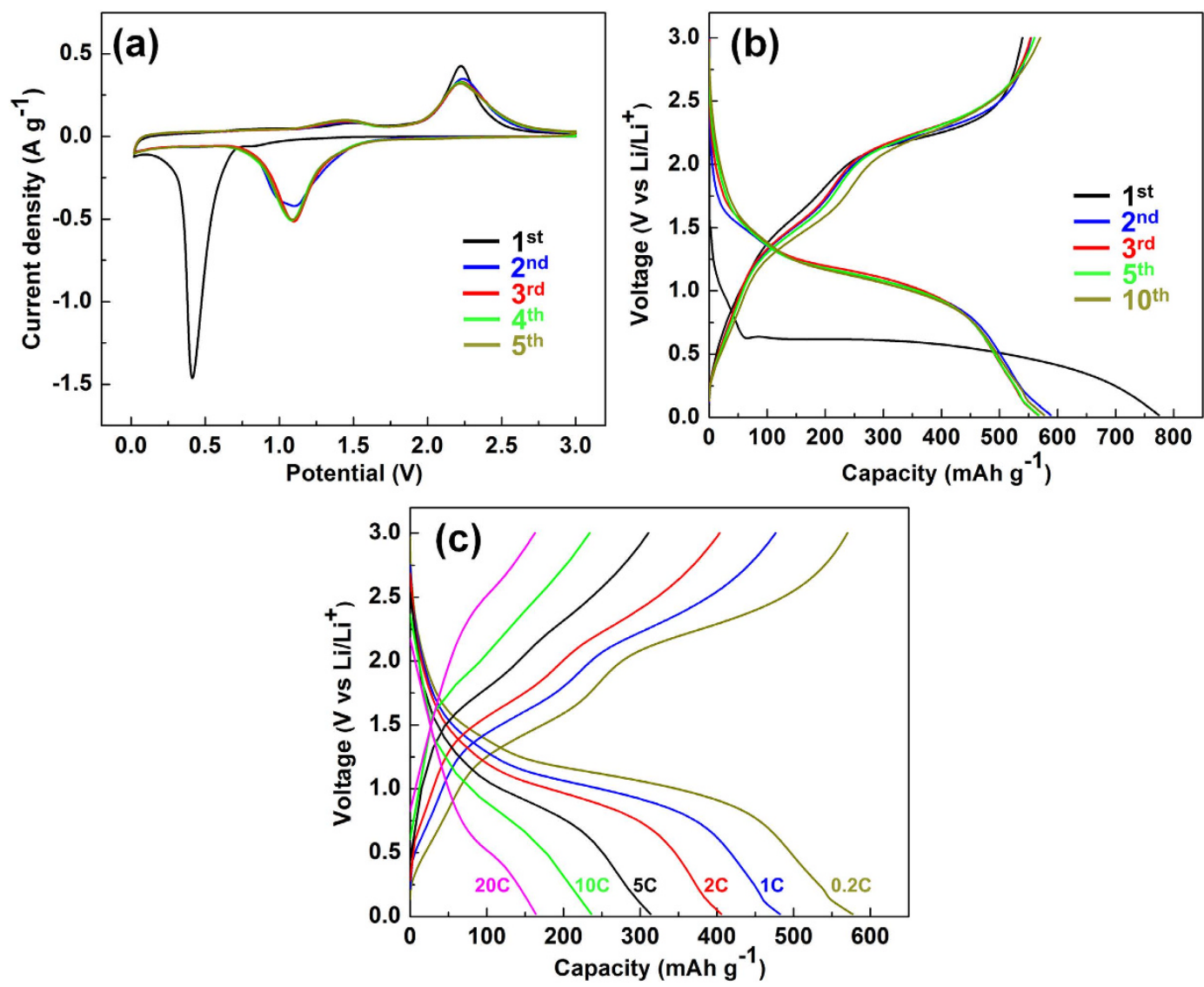

Figure 4. (a) Cyclic voltammetric diagrams of the NiO NWF anode for 5 cycles with $0.1 \mathrm{mV} \mathrm{s}^{-1}$. Chargedischarge curves of $(\mathbf{b})$ selected cycles at $0.2 \mathrm{C}\left(1 \mathrm{C}=718 \mathrm{~mA} \mathrm{~g}^{-1}\right)$ and $(\mathbf{c})$ at various $\mathrm{C}$ rates.

shows stronger signals than that of $\mathrm{Ni}^{3+}$ at ca. $531.2 \mathrm{eV}$ (Fig. 3c), demonstrating that $\mathrm{NiO}$ is the dominant species after air annealing. Signals from $870-885 \mathrm{eV}$ and $850-865 \mathrm{eV}$ correspond to $\mathrm{Ni} 2 \mathrm{p}_{1 / 2}$ and $\mathrm{Ni} 2 \mathrm{p}_{3 / 2}$ levels, respectively ${ }^{8}$. Metallic Ni peak detected in Ni NWF at ca. $852.7 \mathrm{eV}^{19}$ is absent in $\mathrm{NiO} \mathrm{NWF}$, indicating good oxide layer coverage after oxidation without metallic backbone exposed. Peaks at $855.9 \mathrm{eV}$ and $861.4 \mathrm{eV}$ in Ni $2 \mathrm{p}_{3 / 2}$ for Ni NWF further demonstrate $\mathrm{Ni}_{2} \mathrm{O}_{3}$ is the main surface composition, while peaks at $853.8,855.7$ and $860.9 \mathrm{eV}$ for $\mathrm{NiO} \mathrm{NWF}$ can be mainly attributed to $\mathrm{Ni}^{2+}$ from $\mathrm{NiO}^{19}$. Survey spectrum of $\mathrm{Ni}$ and $\mathrm{NiO} \mathrm{NWF}$ are shown in Supplementary Fig. S4.

$\mathrm{NiO}$ NWF is tested as an anode in a two-electrode half-cell configuration with $\mathrm{Li}$ foil as the counter electrode. Cyclic voltammetric $(\mathrm{CV})$ profiles are measured in the potential window $0.02-3.0 \mathrm{~V}$ at the scan rate $0.1 \mathrm{mV} \mathrm{s}^{-1}$ (Fig. 4a). In the cathodic scan of the first cycle, an intense peak at ca. $0.41 \mathrm{~V}$ is attributed to the formation of solid electrolyte interface (SEI) layer, initial reduction of $\mathrm{NiO}$ and formation of $\mathrm{Li}_{2} \mathrm{O}\left(\mathrm{NiO}+2 \mathrm{Li}^{+}+2 \mathrm{e}^{-} \rightarrow\right.$ $\left.\mathrm{Ni}+\mathrm{Li}_{2} \mathrm{O}\right)^{8,9,20}$. In the following cycles, this discharge peak potential becomes weaker and move to ca. $1.09 \mathrm{~V}^{8,9}$. During anodic scan, the broad peak at ca. $1.45 \mathrm{~V}$ and the stronger peak at ca. $2.23 \mathrm{~V}$ correspond to SEI layer decomposition and $\mathrm{NiO}$ formation $/ \mathrm{Li}_{2} \mathrm{O}$ decomposition $\left(\mathrm{Ni}+\mathrm{Li}_{2} \mathrm{O} \rightarrow \mathrm{NiO}+2 \mathrm{Li}^{+}+2 \mathrm{e}^{-}\right)$, respectively ${ }^{8,9,20}$. Charge-discharge potential curves of the $1^{\text {st }}$ to $10^{\text {th }}$ cycles of the NiO NWF anode within the $0.02-3.0 \mathrm{~V}$ voltage window at the current rate $0.2 \mathrm{C}\left(1 \mathrm{C}=718 \mathrm{~mA} \mathrm{~g}^{-1}\right)$ are shown in Fig. $4 \mathrm{~b}$. For the $1^{\text {st }}$ discharge, a potential plateau at ca. $0.6 \mathrm{~V}$ is observed. For the subsequent cycles, the discharge potentials is shifted to a slope from ca. 1.6 to $1.0 \mathrm{~V}$, while the charge potential plateaus at ca. $1.5 \mathrm{~V}$ and $2.2 \mathrm{~V}$ are maintained, which is consistent with the CV results. The $1^{\text {st }}$ cycle Coulombic efficiency $(\mathrm{CE})$ of $70.0 \%$ calculated from $1^{\text {st }}$ cycle charge capacity $\left(541 \mathrm{mAh} \mathrm{g}^{-1}\right)$ divided by $1^{\text {st }}$ cycle discharge capacity $\left(773 \mathrm{mAh} \mathrm{g}^{-1}\right)$ can be attributed to the formation of SEI layer between the active materials and the electrolyte $\mathrm{e}^{8-10}$. The NiO NWF anode demonstrates discharge $\left(577 \mathrm{mAh}^{-1}\right)$ and charge capacity $\left(570 \mathrm{mAh} \mathrm{g}^{-1}\right)$ of the $10^{\text {th }}$ cycle for $\mathrm{CE}$ of $98.8 \%$, suggesting good recyclability of the electrode.

Charge-discharge voltage curves at various current rate from $0.2 \mathrm{C}$ to $20 \mathrm{C}$ are shown in Fig. 4c. Higher overpotentials (lower discharge and higher charge potentials) observed for higher $\mathrm{C}$ rates can be attributed to the kinetic effect of the electrode ${ }^{8}$. Similar curve shapes regardless of current density suggest good stability under high C rates. Discharge capacities at $0.2 \mathrm{C}, 1 \mathrm{C}, 2 \mathrm{C}, 5 \mathrm{C}, 10 \mathrm{C}$ and $20 \mathrm{C}$ are 577, 482, 406, 313, 236 and $164 \mathrm{mAh} \mathrm{g}^{-1}$, respectively (Fig. 5a). Impressively, even at extremely high current rate $\left(50 \mathrm{C}=35900 \mathrm{~mA} \mathrm{~g}^{-1}\right)$, the capacity can still reach $75 \mathrm{mAh} \mathrm{g}^{-1}$. The capacity can be resumed back to ca. $430 \mathrm{mAh} \mathrm{g}^{-1}$ in 2 cycles when the current rate is lowered to $0.2 \mathrm{C}$, and the NiO NWF anode can still be stable for 430 cycles with $460 \mathrm{mAh} \mathrm{g}^{-1}$ at $500^{\text {th }}$ cycle with Coulombic efficiency fluctuates between $99.5-102.6 \%$. The capacity recovery with lower current density can be explained as lower overpotentials of the charge-discharge process leading to longer charge-discharge time and 

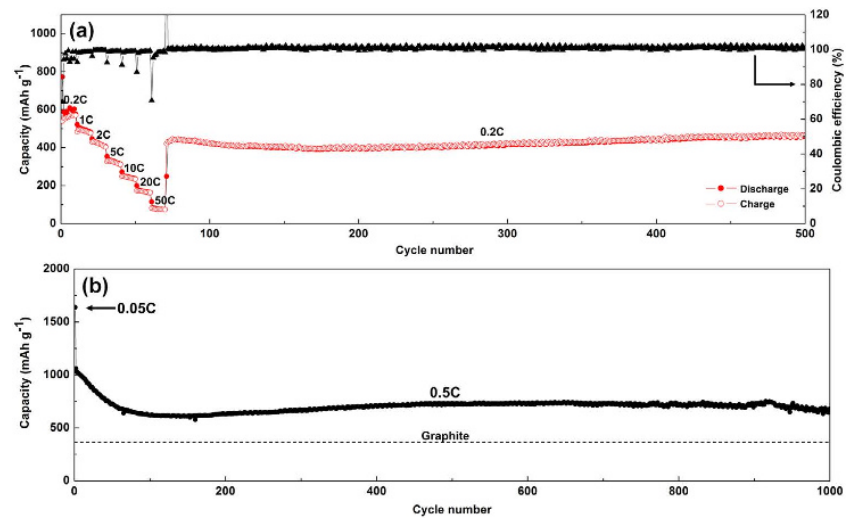

Figure 5. (a) Rate capability of the NiO NWF anode with $\mathrm{C}$ rates ranging from $0.2 \mathrm{C}$ to $50 \mathrm{C}$, and stability at $0.2 \mathrm{C}$ for 430 cycles. (b) Discharge capacity of the NiO NWF anode started with $0.05 \mathrm{C}$ followed by $0.5 \mathrm{C}$ for 1000 cycles comparing with the capacity of graphite.

thus larger capacities in a fixed potential range (i.e. $0.02-3.0 \mathrm{~V}$ ), which is also observed in the literatures ${ }^{8,21-24}$. Failure of the capacity recovery to the values of $0.2 \mathrm{C}$ in the first 10 cycles might be attributed to the nanostructural change after cycling at ultra large current densities (e.g. 20C and 50C). However, the porous nature of the nanowire architecture can accommodate the mechanical strain to a certain degree and maintain its capacities in the following cycling process. The gradual increase in capacity and CE higher than $100 \%$ can be attributed to the activation of anode materials after cycling ${ }^{8,25}$. The superior rate capability can be ascribed to the intimate electrical contact between $\mathrm{NiO}$ active materials and the conductive metallic $\mathrm{Ni}$ support, and the porous framework providing access for the electrolyte resulting in short ionic diffusion length ${ }^{8}$. Compared to the $482 \mathrm{mAh} \mathrm{g}^{-1}$ at $0.72 \mathrm{~A} \mathrm{~g}^{-1}$ of $\mathrm{NiO}$ NWF, recent studies ${ }^{26,27}$ demonstrate higher capacities at similar current densities by decorating $\mathrm{NiO}$ nanosheets onto porous carbon supports, such as sulfonated polystyrene hollow particles (SPS) ${ }^{26}$ with $736 \mathrm{mAh} \mathrm{g}^{-1}$ at $0.8 \mathrm{~A} \mathrm{~g}^{-1}$ and carbon rods (CMK-3) ${ }^{27}$ with $824 \mathrm{mAh} \mathrm{g}^{-1}$ at $0.8 \mathrm{~A} \mathrm{~g}^{-1}$. Even though the high specific surface area of carbon supports promotes the rate capabilities of $\mathrm{NiO}$, relatively lower $1^{\text {st }}$ cycle Coulombic efficiencies $(67 \%$ of SPS, 30-50\% of CMK-3) suggest larger amount of SEI layer formation during the first cycle leading to irreversible $\mathrm{Li}$ consumption of the cathode materials (e.g. $\mathrm{LiCoO}_{2}$ ) and permanent capacity loss when utilized in full cells. Accordingly, improving rate capabilities without compromising $1^{\text {st }}$ cycle Coulombic efficiencies still remains challenging of the state-of-the-art $\mathrm{NiO}$ electrodes.

Cycling stability of the NiO NWF anode is further examined by cycling at $0.05 \mathrm{C}$ for the first cycle followed by $0.5 \mathrm{C}$ for 999 cycles in the potential window $0.02-3.0 \mathrm{~V}$ (Fig. $5 \mathrm{~b}$ ). Superior cycling performance is shown by initially capacity fading to $620 \mathrm{mAh} \mathrm{g}^{-1}$ in 100 cycles, gradually increasing to $735 \mathrm{mAh} \mathrm{g}^{-1}$ at the $500^{\text {th }}$ cycle, holding steadily to $717 \mathrm{mAh} \mathrm{g}^{-1}$ at the $900^{\text {th }} \mathrm{cycle}$, and then slowly decreasing to $680 \mathrm{mAh} \mathrm{g}^{-1}$ at the $1000^{\text {th }} \mathrm{cycle}$, which is notably close to the theoretical value of $\mathrm{NiO}\left(718 \mathrm{mAh} \mathrm{g}^{-1}\right)$ and larger than traditional graphite ${ }^{28}\left(372 \mathrm{mAh} \mathrm{g}^{-1}\right)$ anode. Representative charge-discharge curves from the $100^{\text {th }}$ to $500^{\text {th }}$ cycles (Supplementary Fig. S5a) indicate gradual material activation with less polarization of delithiation. After 500 cycles, discharge curves start to lose the plateau with more polarization ${ }^{8}$, suggesting higher energy necessary for lithiation, while similar charge curves are maintained until reaching the $1000^{\text {th }}$ cycle (Supplementary Fig. S5b).

Higher $\mathrm{NiO}$ loading $\left(1.3 \mathrm{mg} \mathrm{cm}{ }^{-2}\right)$ can be achieved with ramping rate $30^{\circ} \mathrm{C} \mathrm{min}^{-1}$ to higher temperature $\left(500^{\circ} \mathrm{C}\right)$ and kept at $500^{\circ} \mathrm{C}$ for $1 \mathrm{~h}$ in air. Compared to $0.5 \mathrm{mg} \mathrm{cm}^{-2}$, high temperature and elongated annealing time lead to higher $\mathrm{NiO}$ loading with stronger $\mathrm{NiO}$ reflections (Supplementary Fig. S6a). Discharge capacities of $1.3 \mathrm{mg} \mathrm{cm}^{-2} \mathrm{NiO}$ (Supplementary Fig. S6b) are similar to $0.5 \mathrm{mg} \mathrm{cm}^{-2}$ at $1 \mathrm{C}$ and $2 \mathrm{C}$. Nonetheless, capacities diminish to lower values after $5 \mathrm{C}$, which is attributed to the resistive nature of thicker NiO layer resulting in higher overpotentials at large current densities. Higher loading compromises the rate capability of the electrode. Accordingly, to further increase the areal loading, structural optimization could be performed on the NiO NWF, such as increasing areal density of $\mathrm{Ni}$ wire backbone by surface treatment of $\mathrm{Ni}$ foam ${ }^{16}$, decreasing the diameter of $\mathrm{Ni}$ wire by variation of synthetic temperature or $\mathrm{Ni}(\mathrm{Ac})_{2}$ concentrations $\mathrm{s}^{10,12}$, and water concentrations during oxalic acid etching ${ }^{13}$ to modify Ni oxalate nanostructures in the future study.

Superior stability of the NiO NWF is demonstrated in the SEM images after 1000 cycles (Supplementary Fig. $\mathrm{S} 6 \mathrm{c}-\mathrm{e}$ ). Main structure consisting of Ni wire backbone is still intact (Supplementary Fig. S6c-d). While the void space between $\mathrm{NiO}$ nanowires is filled with SEI products (Supplementary Fig. S6e), the shape of nanowires is discernible without obvious cracking or detachment, which further elucidate the ability of accommodation of mechanical strain of the NiO NWF electrode.

Electrochemical impedance spectroscopy (EIS) are performed to further verify the superior electrochemical performance of the NiO NWF anode after one, three and five CV cycles (Fig. 6). The equivalent circuit shown in Fig. 6a is used to fit the impedance data. Experimental results shown in solid symbols (Fig. 6b) are fitted by straight lines using parameters shown in Table 1. Constant phase elements (CPEs) describing non-ideal capacitances with parameters $\mathrm{Q}$ analogous to capacitance and the ideality factor $\mathrm{n}$ are necessitated due to the existence of spatial and chemical non-uniformity across the electrode and the solid electrolyte interphase (SEI) surface ${ }^{29,30}$. $\mathrm{R}_{\mathrm{S}}$ is the equivalent series resistance (ESR) ${ }^{31-33}$, which represents resistances of electrolyte, metallic leads ${ }^{34}$, cell hardware, current collectors and electrode materials ${ }^{35}$. The first parallel impedance branch in the equivalent 

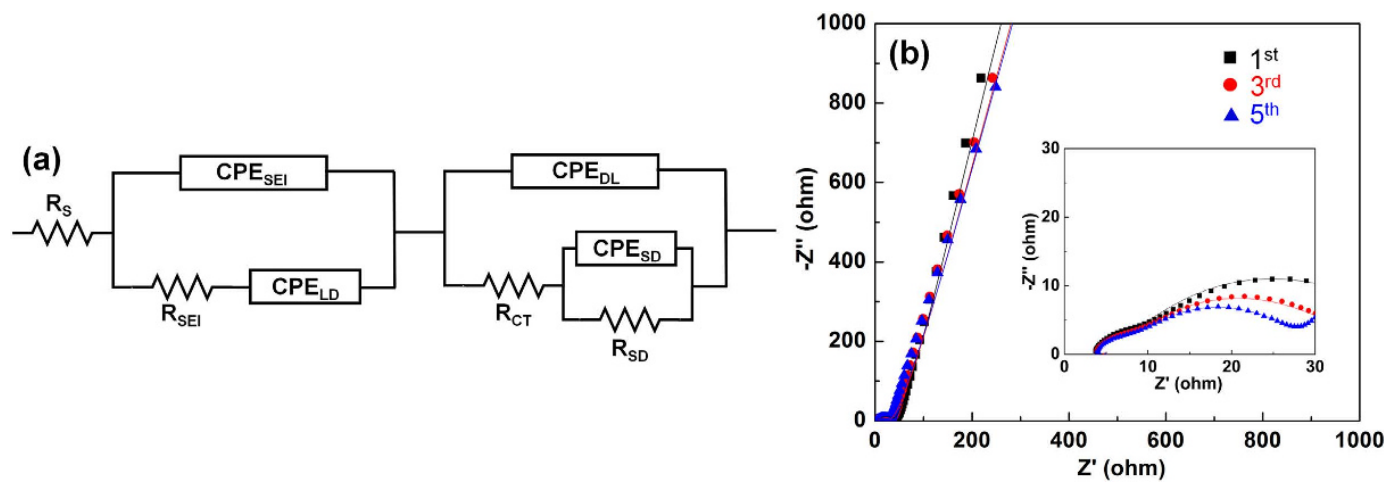

Figure 6. EIS analysis of the NiO NWF with (a) the equivalent circuit and (b) the Nyquist plots of experimental results (solid symbols) and fitted results (solid lines) after 1, 3 and 5 CV cycles.

\begin{tabular}{|c|c|c|c|c|c|c|c|c|c|c|c|c|}
\hline \multirow[b]{2}{*}{ Cycle } & \multirow{2}{*}{$\begin{array}{c}\mathbf{R}_{\mathrm{s}} \\
(\Omega)\end{array}$} & \multirow{2}{*}{$\begin{array}{l}\mathbf{R}_{\text {SEI }} \\
(\Omega)\end{array}$} & \multirow{2}{*}{$\begin{array}{l}\mathbf{R}_{\mathrm{CT}} \\
(\Omega)\end{array}$} & \multicolumn{2}{|c|}{$\mathrm{CPE}_{\mathrm{SEI}}$} & \multicolumn{2}{|l|}{$\mathrm{CPE}_{\mathrm{LD}}$} & \multicolumn{2}{|c|}{$\mathrm{CPE}_{\mathrm{DL}}$} & \multicolumn{2}{|c|}{$\mathrm{CPE}_{\mathrm{SD}}$} & \multirow{2}{*}{$\begin{array}{c}\mathrm{R}_{\mathrm{SD}} \\
(\mathrm{k} \Omega)\end{array}$} \\
\hline & & & & $\mathbf{Q}\left(\mu \mathbf{F ~ s}^{\mathbf{n}-1}\right)$ & n & $\mathrm{Q}\left(\mathrm{mF} \mathrm{s}^{\mathrm{n}-1}\right)$ & $\mathrm{n}$ & $\mathbf{Q}\left(\mu \mathbf{F} \mathbf{s}^{\mathbf{n}-1}\right)$ & n & $\mathrm{Q}\left(\mathrm{mF} \mathrm{s}^{\mathrm{n}-1}\right)$ & $\mathrm{n}$ & \\
\hline $1^{\mathrm{st}}$ & 3.5 & 5 & 30 & 6 & 0.85 & 15 & 0.5 & 70 & 0.75 & 4.5 & 0.93 & 50 \\
\hline $3^{\text {rd }}$ & 3.5 & 5 & 23 & 5 & 0.82 & 15 & 0.5 & 65 & 0.73 & 6 & 0.92 & 50 \\
\hline $5^{\text {th }}$ & 3.5 & 5 & 18.5 & 7 & 0.78 & 16 & 0.5 & 60 & 0.75 & 8 & 0.92 & 50 \\
\hline
\end{tabular}

Table 1. EIS fitting parameters of NiO NWF anode after $1^{\text {st }}, 3^{\text {rd }}$ and $5^{\text {th }} \mathrm{CV}$ cycles.

circuit describes the SEI layers $\left(\mathrm{R}_{\mathrm{SEI}}+\mathrm{CPE}_{\mathrm{SEI}}\right)$ and diffusion of lithium ions in liquid phase near the electrode surface $\left(\mathrm{CPE}_{\mathrm{LD}}\right)$. The second impedance branch accounts for double-layer impedance $\left(\mathrm{CPE}_{\mathrm{DL}}\right)$ and charge transfer resistance $\left(\mathrm{R}_{\mathrm{CT}}\right)$ at the interface of electrolyte and active materials ${ }^{36}$, and diffusion of lithium ions within the solid phase of the electrode $\left(\mathrm{R}_{\mathrm{SD}}+\mathrm{CPE}_{\mathrm{SD}}\right)$. The first and second depressed semicircles (inset of Fig. 6b) with characteristic frequencies at ca. $9470 \mathrm{~Hz}$ and $455 \mathrm{~Hz}$ can be attributed to the SEI layers and charge transfer resistance, respectively ${ }^{37}$. The low frequency impedance tail can be ascribed to lithium diffusion in the electrolyte and active materials ${ }^{35}$, which is represented by $\mathrm{CPE}_{\mathrm{LD}}$ and $\mathrm{CPE}_{\mathrm{SD}}+\mathrm{R}_{\mathrm{SD}}$, respectively.

The results obtained from impedance data fitting demonstrate the stability of the NiO NWF anode. Charge-transfer resistance decreases by $38 \%$ between the first and the fifth cycle, which corresponds to the facilitation of lithium ion diffusion via electrolyte wetting. Resistance corresponding to the SEI layers $\left(\mathrm{R}_{\mathrm{SEI}}\right)$ stays constant throughout the initial cycles. This reveals the formation of stable passivating layers in the first cycle, which alleviates capacity loss with cycling. The ideality n of SEI layers decreases slightly from 0.85 to 0.78 , denoting minimal structural change during the first few cycles. The idealities of double layer capacitance and the diffusion capacitances do not change much, and ESR keeps constant during the initial cycles, which also suggest improved stability of the electrode.

In conclusion, we have developed $\mathrm{NiO}$-decorated $\mathrm{Ni}$ nanowire foam with solution-based synthesis, low temperature hydrogen reduction followed by air annealing process. NiO NWF has been shown as a perspective anode for Li-ion batteries. Excellent stability with minimal capacity fading over 1000 cycles with $680 \mathrm{mAh} \mathrm{g}^{-1}$ at $0.5 \mathrm{C}$, and good rate capability at very high current rates $\left(20 \mathrm{C}\right.$ and $50 \mathrm{C}$, with ca. 164 and $75 \mathrm{mAh} \mathrm{g}^{-1}$, respectively) indicate the superior electrochemical performance of the anode. Superb rate capability and stability can be evidenced with EIS results demonstrating low ESR of ca. $3.5 \Omega$ and stable electrochemical parameters with cycling, respectively. Simple production procedures utilizing liquid-based solution, eco-benign compounds and low temperature render the mass manufacturing of the NiO NWF anode plausible.

\section{References}

1. Bell, J. et al. Free-standing Ni-NiO nanofiber cloth anode for high capacity and high rate Li-ion batteries. Nano Energy 18, 47-56 (2015).

2. Reddy, M. V., Rao, G. V. S. \& Chowdari, B. V. R. Metal Oxides and Oxysalts as Anode Materials for Li Ion Batteries. Chem. Rev. 113, 5364-5457 (2013).

3. Khaligh, A. \& Li, Z. H. Battery, Ultracapacitor, Fuel Cell, and Hybrid Energy Storage Systems for Electric, Hybrid Electric, Fuel Cell, and Plug-In Hybrid Electric Vehicles: State of the Art. IEEE Trans. Veh. Technol. 59, 2806-2814 (2010).

4. Poizot, P., Laruelle, S., Grugeon, S., Dupont, L. \& Tarascon, J. M. Nano-sized transition-metaloxides as negative-electrode materials for lithium-ion batteries. Nature 407, 496-499 (2000).

5. Poizot, P., Laruelle, S., Grugeon, S., Dupont, L. \& Tarascon, J. M. Searching for new anode materials for the Li-ion technology: time to deviate from the usual path. J. Power Sources 97-8, 235-239 (2001).

6. Aravindan, V. et al. Electrospun $\mathrm{NiO}$ nanofibers as high performance anode material for Li-ion batteries. J. Power Sources 227, 284-290 (2013).

7. Yang, W. F. et al. $\mathrm{NiO}$ nanorod array anchored $\mathrm{Ni}$ foam as a binder-free anode for high-rate lithium ion batteries. J. Mater. Chem. A 2, 20022-20029 (2014).

8. Sun, X. L. et al. Three-Dimensionally "Curved" NiO Nanomembranes as Ultrahigh Rate Capability Anodes for Li- Ion Batteries with Long Cycle Lifetimes. Adv. Energy Mater. 4, 1300912 (2014). 
9. Fu, Y. J. et al. Template-free synthesized Ni nanofoams as nanostructured current collectors for high-performance electrodes in lithium ion batteries. J. Mater. Chem. A 1, 10002-10007 (2013).

10. Ni, W., Wu, H. B., Wang, B., Xu, R. \& Lou, X. W. One-Pot Synthesis of Ultra-Light Nickel Nanofoams Composed of Nanowires and Their Transformation into Various Functional Nanofoams. Small 8, 3432-3437 (2012).

11. Haag, J. M., Pattanaik, G. \& Durstock, M. F. Nanostructured 3D Electrode Architectures for High-Rate Li-Ion Batteries. Adv. Mater. 25, 3238-3243 (2013).

12. Ni, W. et al. Hierarchical foam of exposed ultrathin nickel nanosheets supported on chainlike Ni-nanowires and the derivative chalcogenide for enhanced pseudocapacitance. Nanoscale 6, 2618-2623 (2014).

13. Jung, I., Choi, J. \& Tak, Y. Nickel oxalate nanostructures for supercapacitors. J. Mater. Chem. 20, 6164-6169 (2010).

14. Jung, I., Lee, Y., Tak, Y. \& Choi, J. Nickel Oxalate Nanowires Grown on Electrochemically Deposited Ni Thin Film. J. Electrochem. Soc. 158, D123-D126 (2011).

15. Carney, C. S., Gump, C. J. \& Weimer, A. W. Rapid nickel oxalate thermal decomposition for producing fine porous nickel metal powders Part 1: Synthesis. Mater. Sci. Eng., A 431, 1-12 (2006).

16. Liu, C. et al. Scalable, Binderless and Carbonless Hierarchical Ni Nanodendrite Foam Decorated with Hydrous Ruthenium Dioxide for 1.6V Symmetric Supercapacitors. Adv. Mater. Interfaces 3, 1500503 (2016).

17. Kawamori, M. et al. Three-Dimensional Nanoelectrode by Metal Nanowire Nonwoven Clothes. Nano Lett. 14, 1932-1937 (2014).

18. Mironova-Ulmane, N. et al. Raman scattering in nanosized nickel oxide NiO. J. Phys.: Conf. Ser. 93, 012039 (2007).

19. Oswald, S. \& Bruckner, W. XPS depth profile analysis of non-stoichiometric NiO films. Surf. Interface Anal. 36, 17-22 (2004).

20. Huang, X. H. et al. Electrochemical properties of NiO-Ni nanocomposite as anode material for lithium ion batteries. J. Power Sources 161, 541-544 (2006).

21. Wang, X. H. et al. $\mathrm{NiO}$ nanocone array electrode with high capacity and rate capability for Li-ion batteries. J. Mater. Chem. 21, 9988-9990 (2011).

22. Wang, X. H. et al. Nanostructured $\mathrm{NiO}$ electrode for high rate Li-ion batteries. J. Mater. Chem. 21, 3571-3573 (2011).

23. Wang, X. H. et al. Mesoporous $\mathrm{NiO}$ nanosheet networks as high performance anodes for Li ion batteries. J. Mater. Chem. A 1, 4173-4176 (2013).

24. Sun, X. L. et al. Multifunctional $\mathrm{Ni} / \mathrm{NiO}$ hybrid nanomembranes as anode materials for high-rate Li-ion batteries. Nano Energy 9 , $168-175(2014)$

25. Deng, J. W. et al. Naturally Rolled-Up C/Si/C Trilayer Nanomembranes as Stable Anodes for Lithium-Ion Batteries with Remarkable Cycling Performance. Angew. Chem., Int. Ed. 52, 2326-2330 (2013).

26. Liang, J. et al. Construction of hybrid bowl-like structures by anchoring $\mathrm{NiO}$ nanosheets on flat carbon hollow particles with enhanced lithium storage properties. Energy Environ. Sci. 8, 1707-1711 (2015).

27. Fan, Z. Y. et al. Ultrathin $\mathrm{NiO}$ nanosheets anchored on a highly ordered nanostructured carbon as an enhanced anode material for lithium ion batteries. Nano Energy 16, 152-162 (2015).

28. Campbell, B., Ionescu, R., Favors, Z., Ozkan, C. S. \& Ozkan, M. Bio-Derived, Binderless, Hierarchically Porous Carbon Anodes for Li-ion Batteries. Sci. Rep. 5, 14575 (2015).

29. Brug, G. J., Vandeneeden, A. L. G., Sluytersrehbach, M. \& Sluyters, J. H. The Analysis of Electrode Impedances Complicated by the Presence of a Constant Phase Element. J. Electroanal. Chem. 176, 275-295 (1984).

30. Favors, Z. et al. Towards Scalable Binderless Electrodes: Carbon Coated Silicon Nanofiber Paper via Mg Reduction of Electrospun SiO2 Nanofibers. Sci. Rep. 5, 8246 (2015).

31. Wang, W. et al. Silicon Decorated Cone Shaped Carbon Nanotube Clusters for Lithium Ion Battery Anodes. Small 10, 3389-3396 (2014).

32. Wang, W. et al. Monodisperse Porous Silicon Spheres as Anode Materials for Lithium Ion Batteries. Sci. Rep. 5, 8781 (2015).

33. Favors, Z. et al. Scalable Synthesis of Nano-Silicon from Beach Sand for Long Cycle Life Li-ion Batteries. Sci. Rep. 4, 5623 (2014).

34. Gaberscek, M., Moskon, J., Erjavec, B., Dominko, R. \& Jamnik, J. The importance of interphase contacts in Li ion electrodes: The meaning of the high-frequency impedance arc. Electrochem. Solid-State Lett. 11, A170-A174 (2008).

35. Dees, D., Gunen, E., Abraham, D., Jansen, A. \& Prakash, J. Alternating current impedance electrochemical modeling of lithium-ion positive electrodes. J. Electrochem. Soc. 152, A1409-A1417 (2005).

36. Guo, J. C., Sun, A., Chen, X. L., Wang, C. S. \& Manivannan, A. Cyclability study of silicon-carbon composite anodes for lithium-ion batteries using electrochemical impedance spectroscopy. Electrochim. Acta 56, 3981-3987 (2011).

37. Mai, Y. J., Tu, J. P., Xia, X. H., Gu, C. D. \& Wang, X. L. Co-doped NiO nanoflake arrays toward superior anode materials for lithium ion batteries. J. Power Sources 196, 6388-6393 (2011).

\section{Acknowledgements}

Financial support from the University of California Riverside is gratefully acknowledged. XPS measurements were recorded at UCR with support from the National Science Foundation under Grant No. DMR-0958796.

\section{Author Contributions}

C.L., M.O. and C.S.O. designed the experiments and wrote the manuscript. C.L., C.L., K.A. and Z.M. worked on $\mathrm{NiO}$ foam synthesis; analytical materials characterization; battery assembly; electrical characterization including charge-discharge profiles, cyclic voltammetry and electrochemical impedance spectroscopy measurements. M.O. and C.S.O. managed the research team. All authors reviewed the manuscript.

\section{Additional Information}

Supplementary information accompanies this paper at http://www.nature.com/srep

Competing financial interests: The authors declare no competing financial interests.

How to cite this article: Liu, C. et al. Template Free and Binderless NiO Nanowire Foam for Li-ion Battery Anodes with Long Cycle Life and Ultrahigh Rate Capability. Sci. Rep. 6, 29183; doi: 10.1038/srep29183 (2016).

This work is licensed under a Creative Commons Attribution 4.0 International License. The images or other third party material in this article are included in the article's Creative Commons license, unless indicated otherwise in the credit line; if the material is not included under the Creative Commons license, users will need to obtain permission from the license holder to reproduce the material. To view a copy of this license, visit http://creativecommons.org/licenses/by/4.0/ 